\title{
MAXIMUM POWER POINT TRACKING CONTROL OF A LINEAR MAGNETIC-GEARED GENERATOR FOR DIRECT-DRIVE WAVE ENERGY CONVERSION
}

\author{
Wenlong Li, K.T. Chau, and Hua Fan \\ Dept. of Electrical and Electronic Engineering \\ The University of Hong Kong, Hong Kong \\ E-mail: \{wlli; ktchau; huafan\}@eee.hku.hk
}

\begin{abstract}
This paper deals with control of a linear magneticgeared permanent-magnet generator for wave power generation using maximum power point tracking (MPPT) algorithm. Firstly, the linear magnetic-geared permanent-magnet generator structure is presented. The machine modeling is established based on the finite element analysis (FEA). Secondly, by analyzing the dynamic model of the wave power, the MPPT algorithm for directdrive wave power generation is discussed. Then, the performance for maximizing wave power absorption is verified and evaluated by the circuit simulator. The results verify that the MPPT algorithm is valid for the direct-drive wave power generation.
\end{abstract}

\section{INTRODUCTION}

Direct-drive wave energy conversion utilizes the linear machine to directly harness reciprocating wave motion, hence eliminating the bulky linear-torotary transmission mechanism and the associated power losses [1]. In order to match the low frequency and huge force of waves, the linear machine has to be very large, leading to be expensive and difficult to install. Therefore, a machine with high force/torque density is suitable for this application. Recent years witnessed the development of high torque permanent magnet (PM) machines in various topologies for direct-drive application, notably doubly-salient PM machines [2]-[16], flux-reversal PM machines [17]-[18], fluxswitching PM machines [19]-[20], transverse-flux PM machines [21]-[22], magnetic gears and the associated integrated machines [23]-[30], and vernier PM machines [31]-[35], etc. The magnetic gear exhibiting superb high torque-density attracts widely attentions. Moreover, because of its torque transmission characteristics, the magnetic-geared machine can realize the so-called "pseudo-directdrive", which means that features of low-speed operation and high-speed machine design can be retained.

Based on this consideration, a linear magnetic gear can be employed to incorporate with a linear generator for scaling up the low-speed wave motion match with the high-speed linear generator operation

\author{
T.W. Ching \\ Faculty of Science and Technology \\ University of Macau, Macau \\ E-mail: twching@umac.mo
}

In this paper, a novel linear generator, which artfully integrates a linear magnetic gear and a linear permanent magnet (PM) brushless generator, is utilized for Archimedes Wave Swing (AWS) based direct-drive wave power generation. When the floater of the AWS is under the crest of a wave, the chamber of the AWS is constricted; and when the floater is under the trough of the wave, the chamber stretches, as shown in Fig. 1. The translator of the linear generator is connected to the axis of the floater, and moves up and down to generate electricity. With the use of the linear magneticgeared generator, the velocity of the heaving floater along with reciprocating wave can be significantly amplified for driving the linear generator, hence offering larger output voltage and higher power density than the low-speed counterpart, and higher efficiency and higher reliability than the mechanical gear counterpart.

Due to the reciprocating wave motion, the generator output exhibits fluctuating power with varying voltage and frequency. In order to efficiently and effectively absorb and harvest the wave power, power conditioning is required. The maximum power point tracking (MPPT) is a well-known control technique which can enable a photovoltaic power system to operate at its maximum power capability under various environmental conditions. Similar to the photovoltaic power system, wave power generation system also exhibits a variable voltage-current characteristic under the variable sea conditions. Therefore, the MPPT technique can be borrowed for power conditioning in wave energy conversion.

In this paper, a linear magnetic-geared generator is designed and implemented for AWS based wave energy conversion. For maximizing the absorbed power, a MPPT algorithm is applied for harnessing the maximum power from the wave motion. Also, a voltage source converter (VSC) connected by a dclink to the linear generator is adopted for dealing with the power flow from the generator to the load/grid. In Section 1, the motivation of this paper will be introduced. In Section 2, design of the linear magnetic-geared generator will be established. In Section 3, the proposed MPPT technique for directdrive wave energy conversion will be discussed. Section 4 will be devoted to evaluate the proposed 
power conditioning system. Simulated results are given to verify the validity of the proposed system.

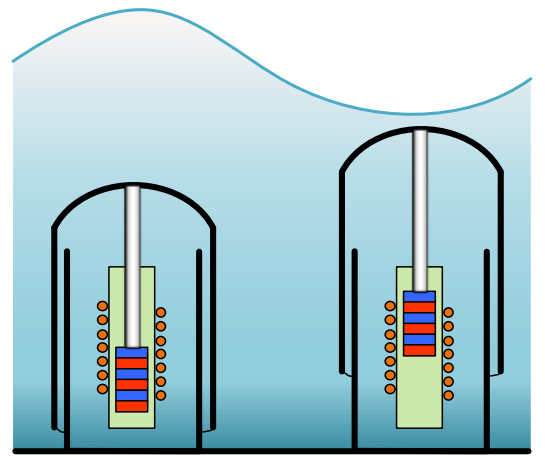

Fig. 1. Archimedes wave swing.

\section{SYSTEM CONFIGURATION}

\subsection{Linear Magnetic Gear}

The linear magnetic gear has distinct advantages, such as physical isolation between moving parts, no mechanical wear and tear, low acoustic noise, and inherent overload protection. Fig. 2 illustrates the topology of a tubular linear magnetic gear. It consists of a high-speed mover, a low-speed mover, and stationary field-modulation rings sandwiched leaving two air-gaps between them. PMs are surface-mounted on the two movers which are laminated by iron sheets. The stationary fieldmodulation rings are also built by laminated iron sheets with epoxy filled in the slots to enhance its structural robustness. Due to the field-modulation rings, magnetic fields of different pole-pair numbers produced by the PMs on the two movers can interact together to develop a steady transmission force when satisfying the following equations:

$$
\begin{aligned}
& N_{s}=N_{l m}+N_{h m} \\
& G_{r}=\frac{v_{h m}}{v_{l m}}=\frac{N_{l m}}{N_{h m}}
\end{aligned}
$$

where $N_{l m}$ and $N_{h m}$ are the numbers of active PM pole-pairs on the low-speed mover and the highspeed mover, respectively, $N_{s}$ is the number of active field-modulation ferromagnetic rings in the stator, $v_{l m}$ and $v_{h m}$ are the velocities of the low-speed mover and the high-speed mover, respectively, and $G_{r}$ is the magnetic gear ratio.

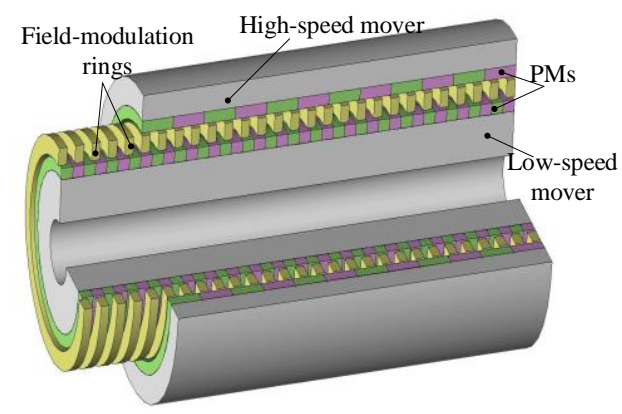

Fig. 2. Tubular linear magnetic gear.

\subsection{Linear PM brushless Machine}

By using the linear magnetic gear for force transmission and speed improvement, the linear generator can adopt the conventional high-speed machine topologies, such as induction machine, synchronous machine, PM brushless machine and switched reluctance machine, etc. Based on considerations of the power density, the torque density and the efficiency, the linear PM brushless machine is the most suitable candidate.

For matching the linear magnetic gear, an 8-pole/6slot tubular linear PM brushless machine is designed as show in Fig. 3. The linear PM brushless machine consists of a stator and a translator. The stator has six slots which house the concentrated armature winding. The rotor has 8 PM poles mounted on the rotor yoke.

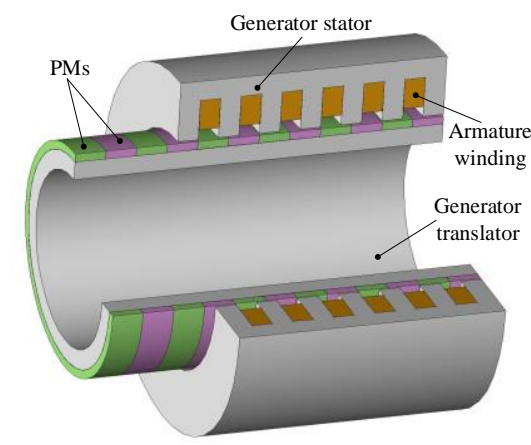

Fig. 3. Tubular Linear PM brushless machine.

\subsection{Linear Magnetic-geared Machine}

There are two possible ways to integrate the linear magnetic gear with the linear PM machine, namely the series integration and the parallel integration. For series integration, only mechanical coupling is achieved and the magnetic circuits of the linear magnetic gear and the linear PM machine are isolated. For the parallel integration, the magnetic gear and the machine share the high-speed mover, which results in both mechanical and magnetic coupling. As shown in Fig. 4, the integrated machine consists of a linear magnetic gear sandwiched by a linear PM brushless machine, thus artfully sharing with the same shaft (the high-speed mover of the gear and the translator of the generator). It has two moving parts and two stationary parts separated by three air-gaps. For mechanical realization, three sets of linear bearing should be involved for supporting the two moving parts.

The key design data for the linear magnetic-geared machine are listed in Table I. By using the finite element method, the characteristics of the linear magnetic gear and the linear PM brushless machine can be obtained. Fig. 5 shows the static force waveforms of the low-speed mover and high-speed 
mover. It can be found that the force is reduced by 2.75 times due to the magnetic gearing effect.

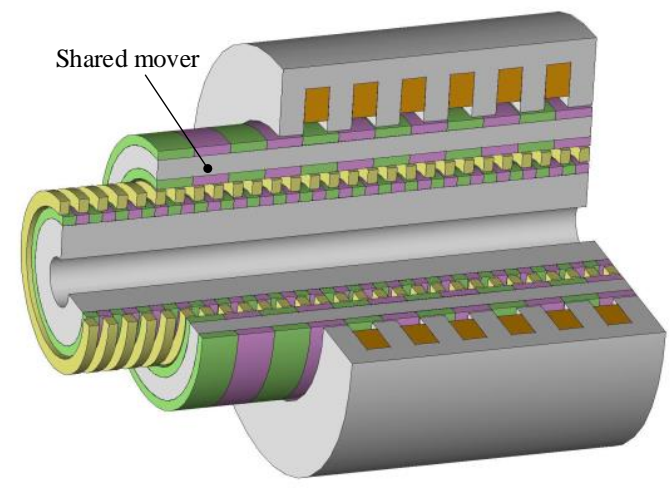

Fig.4. Linear magnetic-geared generator.

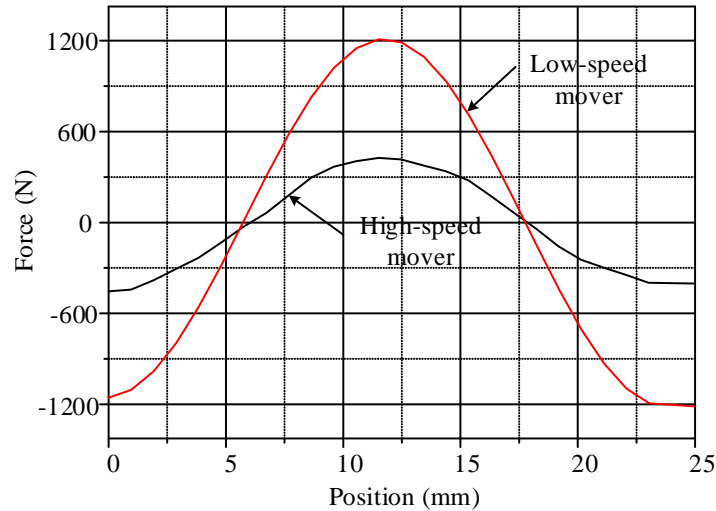

Fig. 5. Static force waveforms.

TABLE I. DESIGN DATA OF LiNEAR MAGNETIC-GEARED MACHINE

\begin{tabular}{ll}
\hline \hline Gear & \\
\hline Gear inside diameter & $10 \mathrm{~mm}$ \\
Gear outside diameter & $50 \mathrm{~mm}$ \\
Gear active length & $150 \mathrm{~mm}$ \\
Gear low-speed mover inside diameter & $10 \mathrm{~mm}$ \\
Gear low-speed mover outside diameter & $29 \mathrm{~mm}$ \\
Mass of gear low-speed mover & $2.4 \mathrm{~kg}$ \\
Gear high-speed mover inside diameter & $37 \mathrm{~mm}$ \\
Gear high-speed mover outside diameter & $50 \mathrm{~mm}$ \\
Gear stationary ferromagnetic ring thickness & $6 \mathrm{~mm}$ \\
Mass of gear high-speed mover & $4.2 \mathrm{~kg}$ \\
Air-gap length & $1.0 \mathrm{~mm}$ \\
No. of active pole-pairs in low-speed mover & 11 \\
No. of active stationary ferromagnetic rings & 15 \\
No. of active pole-pairs in high-speed mover & 4 \\
PM remanence & $1.2 \mathrm{~T}$ \\
\hline \hline Linear generator & 3 \\
\hline No. of phases & $160 \mathrm{~V}$ \\
Rated voltage & $2.75 \mathrm{~m} / \mathrm{s}$ \\
Rated speed & 100 \\
No. of turns per slot & $41 \mathrm{~mm}$ \\
Generator translator inside diameter & $54 \mathrm{~mm}$ \\
Generator translator outside diameter & $100 \mathrm{~mm}$ \\
Generator translator active length & $4.2 \mathrm{~kg}$ \\
Mass of generator translator & $55 \mathrm{~mm}$ \\
Generator stator inside diameter & $85 \mathrm{~mm}$ \\
Generator stator outside diameter & $108.3 \mathrm{~mm}$ \\
Generator stator axial length & $95.3 \mathrm{mH}$ \\
Synchronous inductance & \\
\hline \hline
\end{tabular}

\section{CONTROL ALGORITHM}

As shown in Fig. 1, the heaving floater is coupled to the low-speed mover and the low-speed high wave heaving force is converted into a high-speed low driving force to drive the generator translator. Its motion is governed by:

$$
F_{e}+F_{r}+F_{s}+F_{d}+m g=m G_{r}^{2} \frac{d^{2} x}{d t^{2}}
$$

where $F_{e}$ is the excitation force of coming waves exerting on the floater, $F_{d}$ is the generator damping force, $g$ is the gravitational acceleration, $m$ is the mass of the shared mover, and $x$ is the displacement of the shared mover.

The radiation force is given by [36]:

$$
F_{r}=A(\omega) G_{r}^{2} \frac{d^{2} x}{d t^{2}}+B(\omega) G_{r} \frac{d x}{d t}
$$

where $A(\omega)$ is the added mass around the floater and $B(\omega)$ is the energy loss due to the incident waves.

The hydrostatic force is given by [36]:

$$
F_{s}=\rho g S_{a} x
$$

where $\rho$ is the density of water and $S_{a}$ is the wetted area of the floater.

The damping force of the linear generator is given by [36]:

$$
F_{d}=\gamma G_{r} \frac{d x}{d t}+K x
$$

where $\gamma$ is the force coefficient related to the velocity and $K$ is the hydrodynamic stiffness.

Therefore, by combining (6)-(9), the excitation force of the coming waves can be expressed as:

$$
F_{e}=[m+A(\omega)] G_{r}^{2} \frac{d^{2} x}{d t^{2}}+[\gamma+B(\omega)] G_{r} \frac{d x}{d t}+\left(\rho g S_{a}+K\right) x
$$

The maximum power absorption is obtained when the natural frequency of the wave energy converter coincides with the wave frequency which means that the velocity of the point-absorber is in phase with the excitation force $F_{e}$ [37]-[39]. Therefore, the impedance of the linear generator should be the complex conjugate of the wave energy converter to ensure maximum power absorption.

\section{PERFORMANCE VERIFICATION}

For verifying performances of the MPPT algorithm, the linear magnetic-geared is connected to a dc source via a VSC which enables the bi-directional power flow between the generator and the dc source.

By controlling the generator thrust, the impedance of the generator can be similar as the complex 
conjugate of the wave energy converter. Therefore, the wave energy converter can resonantly operate with the incident waves and the absorbed power can be maximized. By using the field-oriented control, the reference signal of quadrature-axis current can be calculated based on the translator velocity information. Then, the actual current signal is compared with the current reference signal for obtaining the error signals which are feed into a PI controller for generating a set of control pulse signal. With these firing signals, power switches of VSC are turned on and off for tracing the reference signal. By using VSC, the power can flow bi-directionally for ensuring the wave energy converter to resonate with the waves.

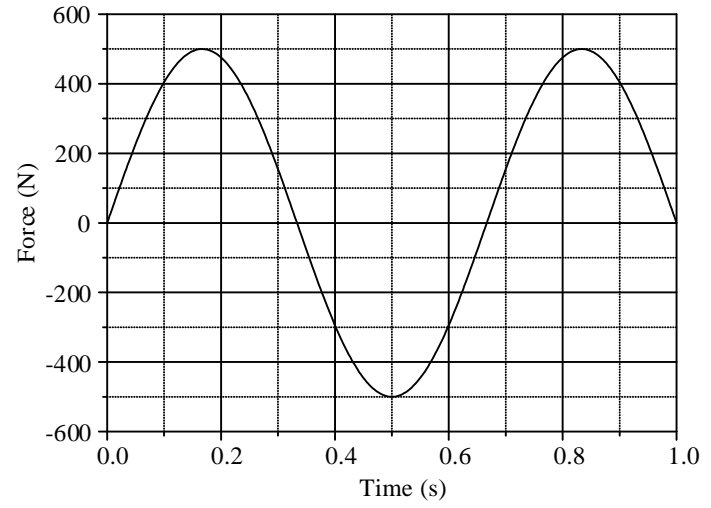

Fig. 6. Force waveform of incident waves.

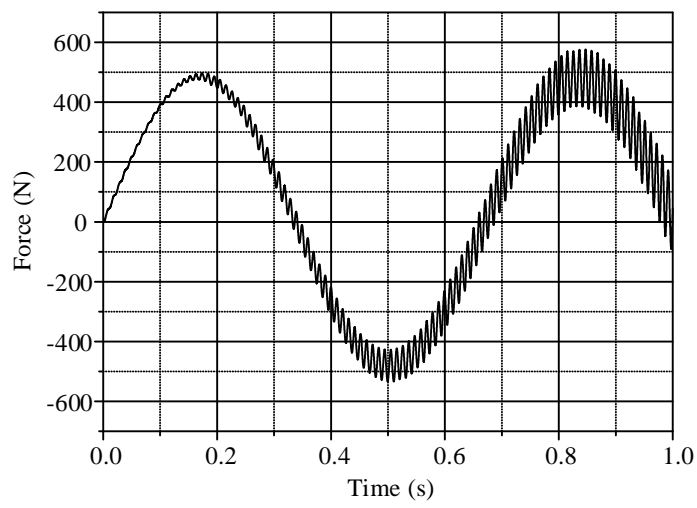

Fig. 7. Force waveform of the low-speed mover.

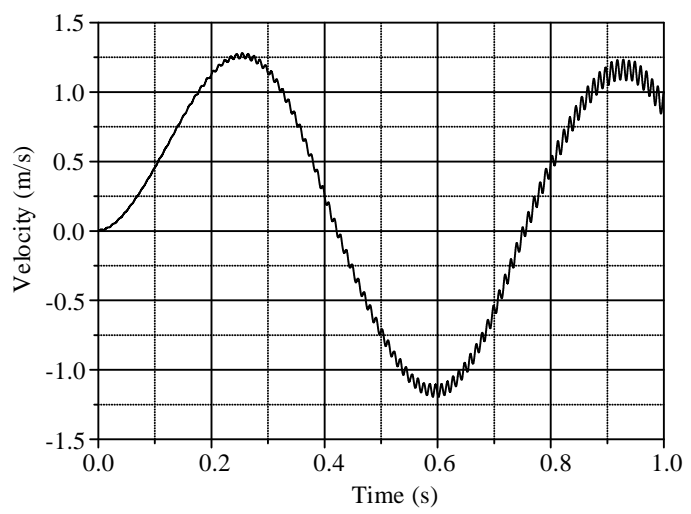

Fig. 8. Velocity of the low-speed mover.

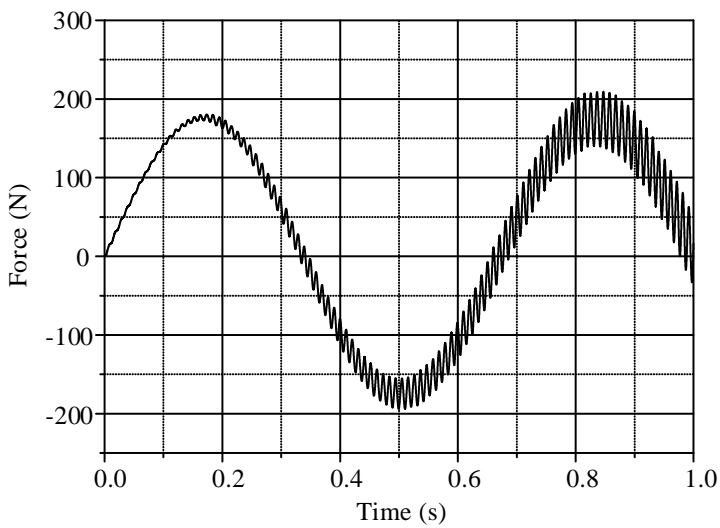

Fig. 9. Force waveform of the high-speed mover.

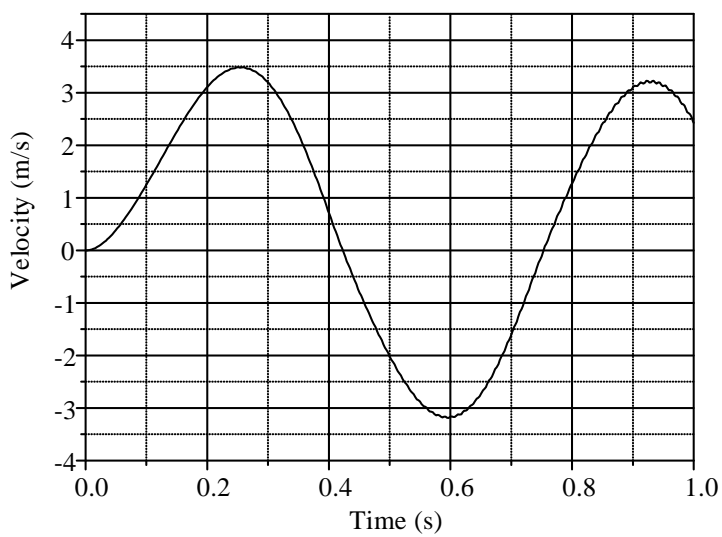

Fig. 10. Velocity of the high-speed mover.

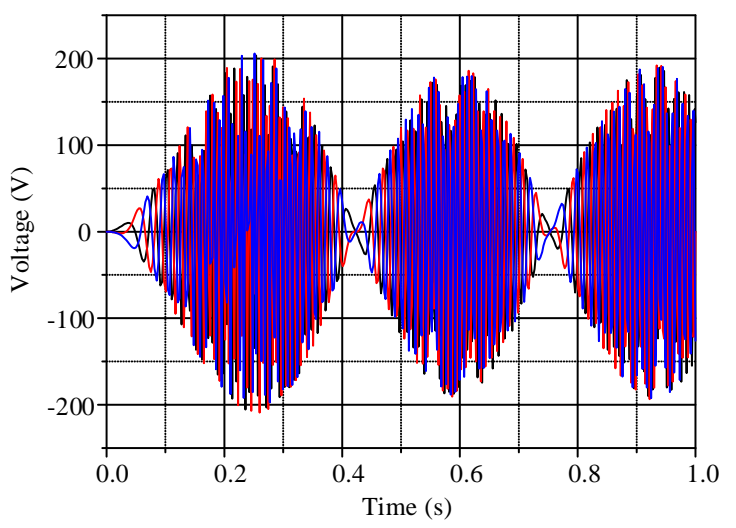

Fig. 11. No-load EMF waveforms.

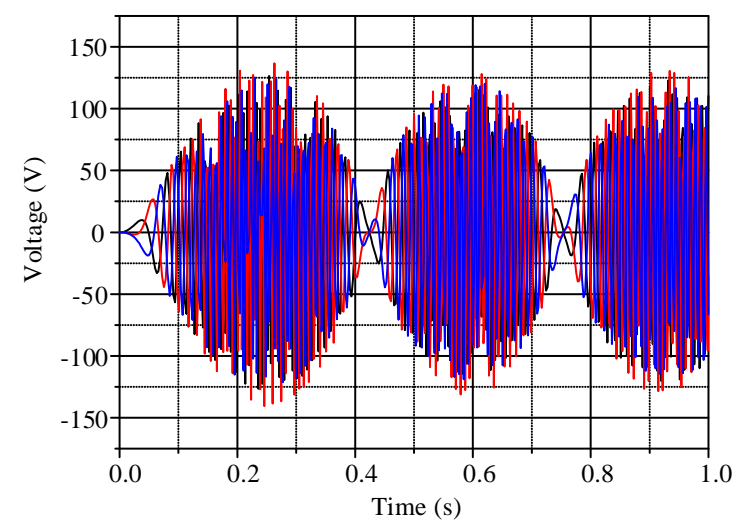

Fig. 12. Terminal voltage waveforms. 


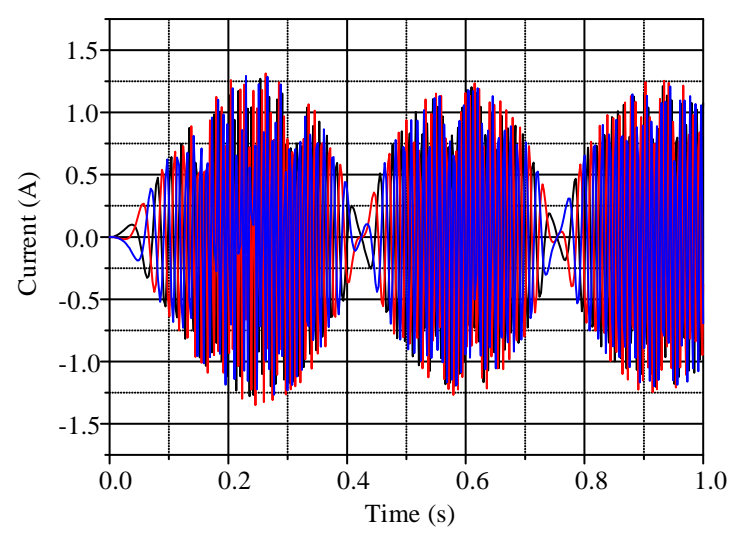

Fig. 13. Current waveforms.

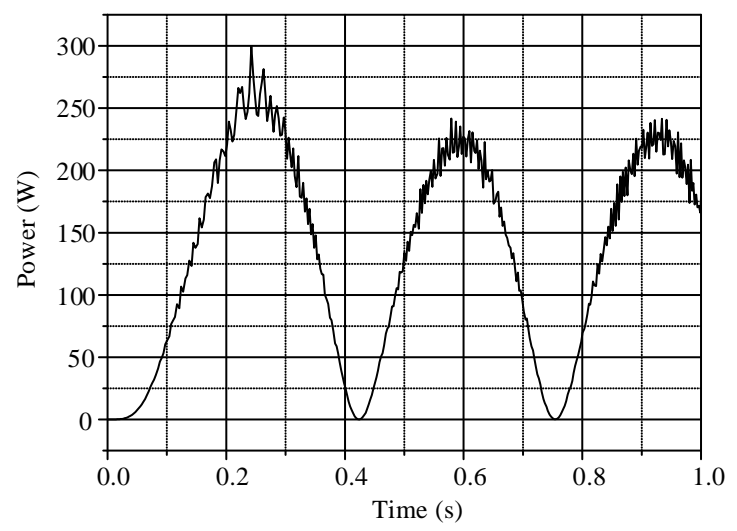

Fig. 14. Active power absorbed by the linear magnetic-geared generator.

Monochromatic waves which exert on the floater of AWS are considered in this paper. Fig. 6 shows the force exerted on the buoy which is sinusoidal with amplitude of $500 \mathrm{~N}$ and a frequency of $1.5 \mathrm{~Hz}$. Since the floater is coupled to the low-speed mover of the linear magnetic-geared generator, the low-speed mover is driven by the floater and the high-speed mover is driven by the low-speed mover with speed amplification. Fig. 7 and Fig. 8 show the thrust force and speed waveforms of the low-speed mover, respectively. The speed of the low-speed mover is sinusoidal with amplitude of 1.27. Fig. 9 and Fig. 10 illustrate the thrust force and speed waveforms of the high-speed mover, respectively. The force of the high-speed mover is also sinusoidal with amplitude of $180 \mathrm{~N}$. The speed of the high-speed mover is sinusoidal with amplitude of 3.5 . The force of the waves is scaled down by a ratio of 2.75 via the linear magnetic gear and the speed of the shared mover is scaled up by a ratio of 2.75 . The low-speed and high-force-density of wave energy is transformed into an energy source with a high-speed and low-force-density feature.

Fig. 11 illustrates the no-load voltage waveforms of the linear magnetic-geared generator. Its amplitude is about 200V. Fig. 12 and Fig. 13 show the terminal voltage and current waveforms. The voltage amplitude is about $120 \mathrm{~V}$. Since the speed is scaled up by the linear magnetic gear, the voltage amplitude of the linear generator is improved. By comparing waveforms in Fig. 12 and Fig.13, it can be observed that with the MPPT algorithm and fieldoriented control, the current is nearly in phase with the voltage waveform. Also, in Fig. 9, the translator force waveform has a correct phase relationship with the force waveform of incident waves. Due to the control of the linear generator force, the wave energy converter operates in resonance with the incident waves. Therefore, the maximum power can be absorbed from the wave energy. Fig. 14 shows the absorbed power waveforms of the linear magnetic-geared generator. The active power has amplitude of $230 \mathrm{~W}$ which is transferred to the dclink via VSC.

\section{CONCLUSIONS}

In this paper, a linear magnetic-geared generator is applied for the AWS based direct-drive wave energy conversion. In order to absorb the maximized power, the MPPT algorithm is adopted for regulating the generator force for making the wave energy converter operating resonantly with the incident waves. The linear magnetic gear and the linear PM generator parameters are calculated based on FEM. Then, the mathematical modeling the linear magnetic-geared generator is established. The maximum power absorption condition and the MPPT algorithm are studied. For verifying the performance of the MPPT algorithm, the linear magnetic-geared generator is connected to a dc source via a full-bridge VSI which can enable the bidirectional power flow. Therefore, the AWS based wave energy converter can operate resonantly with the incident waves. The simulation results verify that the absorbed power by the linear magneticgeared generator can be maximized by using the MPPT control algorithm.

\section{ACKNOWLEDGMENTS}

This work was supported in part by a grant (Project No. HKU710711E) from the Hong Kong Research Grants Council, Hong Kong Special Administrative Region, China and a grant (Project No. 201309176197) from The University of Hong Kong, Hong Kong, China.

\section{REFERENCES}

[1] H. Polinder, B.C. Mecrow, A.G. Jack, P.G. Dickinson, and M.A. Mueller, "Conventional and TFPM linear generators for direct-drive wave energy conversion," IEEE Transactions on Energy Conversion, vol. 20, no. 2, June 2005, pp. 260- 267.

[2] K.T. Chau, M. Cheng, and C.C. Chan, "Performance analysis of 8/6-pole doubly salient permanent magnet motor," Electric Machines and Power Systems, vol. 27, no. 10, October 1999, pp. 1055-1067.

[3] K.T. Chau, M. Cheng and C.C. Chan, "Nonlinear magnetic circuit analysis for a novel stator-doubly-fed doubly-salient 
machine," IEEE Transactions on Magnetics, vol. 38, no. 5, September 2002, pp. 2382-2384.

[4] M. Cheng, K.T. Chau and C.C. Chan, "New split-winding doubly salient permanent magnet motor drive," IEEE Transactions on Aerospace and Electronic Systems, vol. 39, no. 1, January 2003, pp. 202-210.

[5] K.T. Chau, Q. Sun, Y. Fan and M. Cheng, "Torque ripple minimization of doubly salient permanent magnet motors," IEEE Transactions on Energy Conversion, vol. 20, no. 2, June 2005, pp. 352-358.

[6] Y. Fan, K.T. Chau and M. Cheng, "A new three-phase doubly salient permanent magnet machine for wind power generation," IEEE Transactions on Industry Applications, vol. 42, no. 1, January/February 2006, pp. 53-60.

[7] K.T. Chau, Y.B. Li, J.Z. Jiang and C. Liu, "Design and analysis of a stator-doubly-fed doubly-salient permanentmagnet machine for automotive engines," IEEE Transactions on Magnetics, vol. 42, no. 10, October 2006, pp. 3470-3472.

[8] Y. Gong, K.T. Chau, J.Z. Jiang, C. Yu and W. Li, "Analysis of doubly salient memory motors using Preisach theory," IEEE Transactions on Magnetics, vol. 45, no. 10, October 2009, pp. 4676-4679.

[9] W. Zhao, K.T. Chau, M. Cheng, J. Ji and X. Zhu, "Remedial brushless AC operation of fault-tolerant doubly-salient permanent-magnet motor drives," IEEE Transactions on Industrial Electronics, vol. 57, no. 6, June 2010, pp. 21342141.

[10] C. Liu, K.T. Chau, J.Z. Jiang and L. Jian, "Design of a new outer-rotor permanent magnet hybrid machine for wind power generation," IEEE Transactions on Magnetics, vol. 44, no. 6, June 2008, pp. 1494-1497.

[11] C. Liu, K.T. Chau and X. Zhang, "An efficient windphotovoltaic hybrid generation system using doubly-excited permanent-magnet brushless machine," IEEE Transactions on Industrial Electronics, vol. 57, no. 3, March 2010, pp. 831-839.

[12] C. Liu, K.T. Chau and W. Li, "Comparison of fault-tolerant operations for permanent-magnet hybrid brushless motor drive," IEEE Transactions on Magnetics, vol. 45, no. 6, June 2010, pp. 1378-1381.

[13] S. Niu, K.T. Chau, J.Z. Jiang and C. Liu, "Design and control of a new double-stator cup-rotor permanent-magnet machine for wind power generation," IEEE Transactions on Magnetics, vol. 43, no. 6, June 2007, pp. 2501-2503.

[14] C. Yu, K.T. Chau, X. Liu and J.Z. Jiang, "A flux-mnemonic permanent magnet brushless motor for electric vehicles," Journal of Applied Physics, vol. 103, no. 7, April 2008, paper no. 07F103, pp. 1-3.

[15] X. Zhu, K.T. Chau, M. Cheng and C. Yu, "Design and control of a flux-controllable stator-permanent magnet brushless motor drive," Journal of Applied Physics, vol. 103, no. 7, April 2008, paper no. 7F134, pp. 1-3.

[16] W. Li, K.T. Chau, Yu Gong, J.Z. Jiang, and F. Li, “A new flux-mnemonic dual-magnet brushless machine," IEEE Transactions on Magnetics, vol.47, no.10, 2011, pp.42234226.

[17] S.-U. Chung, H.-J. Lee, and S.-M. Hwang, "A novel design of linear synchronous motor using FRM Topology," IEEE Trans. Magn., vol. 44, no. 6, pp. 1514-1517, 2008.

[18] TH Kim, "A study on the design of an inset-permanentmagnet-type flux-reversal machine," IEEE Transactions on Magnetics, vol. 45, no. 6, pp. 2859-2862, 2009.

[19] Z.Q Zhu and D Howe, "Electrical machines and drives for electric, hybrid, and fuel cell vehicles," Proceedings of the IEEE, vol. 95, no. 4, pp.746-765, 2007.

[20] W.X. Zhao, M. Cheng, K.T. Chau, W. Hua, H. Jia, J. Ji and W. Li, "Stator-flux-oriented fault-tolerant control of fluxswitching permanent- magnet motor," IEEE Transactions on Magnetics, vol. 47, no. 10, October, 2011, pp.4191-4194.

[21] J. Wang, K.T. Chau, J.Z. Jiang and C. Yu, "Design and analysis of a transverse flux permanent magnet machine using three dimensional scalar magnetic potential finite element method," Journal of Applied Physics, vol. 103, no. 7, April 2008, pp. 7F107:1-3.

[22] W. Li and K.T. Chau, "Design and analysis of a novel linear transverse flux permanent magnet motor using HTS magnetic shielding," IEEE Transactions on Applied Superconductivity, vol. 20, no. 3, June 2010, pp. 1106-1109.

[23] L. Jian, K.T. Chau, Y. Gong, J.Z. Jiang, C. Yu and W. Li, "Comparison of coaxial magnetic gears with different topologies," IEEE Transactions on Magnetics, vol. 45, no. 10, October 2009, pp. 4526-4529.

[24] L. Jian, K.T. Chau and J. Z. Jiang, "A magnetic-geared outer-rotor permanent-magnet brushless machine for wind power generation," IEEE Transactions on Industry Applications, vol. 45, no. 3, 954-962, May/June, 2009.

[25] W. Li, K.T. Chau, and J. Li, "Simulation of a tubular linear magnetic gear using HTS bulks for field modulation," IEEE Transactions on Applied Superconductivity, vol.21, no.3, 2010, pp.1167-1170.

[26] R.C. Holehouse, K. Atallah, and J. Wang, "Design and realization of a linear magnetic gear," IEEE Transactions on Magnetics, vol. 47, no. 10, 4171-4174, 2011.

[27] W. Li and K.T. Chau, "A linear magnetic-geared free-piston generator for range-extended electric vehicles," Journal of Asian Electric Vehicles, vol. 8, no. 1, June 2010, pp. 13451350 .

[28] W. Li, K. T. Chau, and J. Z. Jiang, "Application of linear magnetic gears for pseudo-direct-drive oceanic wave energy harvesting," IEEE Transactions on Magnetics, vol. 47, no. 10, October 2011, pp. 2624-2627.

[29] W. Li and K.T. Chau, "Analytical field calculation for linear tubular magnetic gears using equivalent anisotropic magnetic permeability," Progress In Electromagnetics Research, vol. 127, April 2012, pp. 155-171.

[30] M. Chen, K.T. Chau, W. Li, and C. Liu, "Development of non-rare-earth magnetic gears for electric vehicles," Journal of Asian Electric vehicles, vol. 10, no.2, 2012, pp. 16071613

[31] J. Li, K.T. Chau, J.Z. Jiang, C. Liu, and W. Li, "A new efficient permanent-magnet vernier machine for wind power generation," IEEE Transactions on Magnetics, vol. 45, no. 6, June 2010, pp. 1475-1478.

[32] C. Liu, J. Zhong, and K.T. Chau, "A novel fluxcontrollable vernier permanent-magnet machine," IEEE Transactions on Magnetics, vol. 47, no. 10, October 2011, pp. 4238-4241.

[33] W. Li, K.T. Chau, C. Liu, S. Gao, and D. Wu, "Analysis of tooth-tip flux leakage in surface-mounted permanent magnet linear vernier machines," IEEE Transactions on Magnetics, vol. 49, no. 7, July 2013, pp.3949-3952.

[34] K.T. Chau and W. Li, "Overview of Electric Machines for Electric and Hybrid Vehicles," International Journal of Vehicle Design , vol. 64, no. 1, 2014, pp.46-71.

[35] W. Li, K.T. Chau, C. Liu, and C. Qiu, "Design and analysis of a flux-controllable linear variable reluctance machine," IEEE Transactions on Applied Superconductivity, vol. 24, no. 3, 2014, pp. 5200604:1-4.

[36] R. Ekstrom, B. Ekergard, and M. Leijon, "Electrical damping of linear generators for wave enerngy converters-A review," Renewable and Sustainable Energy Reviews, vol. 42, 2015, pp.116-128.

[37] E.A. Amon, T.K.A. Brekken, and A.A. Schacher, "Maximum power point tracking for ocean wave energy conversion," IEEE Transactions on Industry Applications, vol. 48, no. 3, 2012, pp.1079-1086.

[38] J. Falnes. Ocean waves and oscillating systems: linear interactions including wave-enenrgy extraction. Cambridge University Press, 2002.

[39] E. Tedeschi and M. Molinas, "Control strategy of wave energy converters optimized under power electronics rating constraints," Proceeding of 3rd International Conference on Ocean Energy, October 6-8, 2010, Bilbao, Spain. 